\title{
Status Ontológico da Teoria do Discurso (TD) em Laclau e Mouffe: Diálogos, Perspectivas Teóricas e Conceitos Básicos*
}

\author{
Marcelo de Souza Marques \\ Doutorando em Sociologia na Universidade Federal do Rio Grande do Sul (UFRGS). Porto Alegre, RS. \\ Brasil. \\ E-mail: marcelo.marques.cso@gmail.com, https://orcid.org/0000-0003-2395-0191.
}

\section{INTRODUÇÃO}

$\mathrm{O}$ objetivo deste artigo é retomar algumas discussões teórico-filosóficas que ajudam a delinear o status ontológico do pensamento de Laclau e Mouffe. Esse exercício se faz necessário uma vez que algumas questões que fundamentam a Teoria do Discurso (TD) nem sempre são expostas pelos autores de forma mais desenvolvida, o que pode dificultar a apreensão da teoria por parte dos públicos menos familiarizados com as discussões teóricas e epistemológicas mobilizadas por Laclau e Mouffe. Com isso, espero contribuir para uma melhor compreensão de conceitos fundantes da referida teoria.

Contudo, vale ressaltar que não se inclui neste objetivo uma apresentação de todo o arcabouço teórico-filosófico que fundamenta o pensamento dos autores, uma vez que isto exigiria um trabalho mais amplo. O foco consistirá na discussão sobre a crítica pós-fundacionalista e pós-estruturalista, as ideias de sedimentação e reativação e, por fim, as noções de sobredeterminação e totalidade social. Entendo que esse primeiro movimento é fundamental para uma melhor compreensão de conceitos centrais da TD, como os de estruturação discursiva, prática articulatória, exterior constitutivo e pontos nodais.

\footnotetext{
* Agradeço aos pareceristas anônimos da Revista DADOS pelas críticas e observações apresentadas. Todas as observações, sugestões e críticas me permitiram rever alguns pontos do artigo. Eventuais lacunas ou imprecisões são de minha inteira responsabilidade.
} 
Ademais, vale chamar a atenção dos leitores, sobretudo aqueles que ainda não estão familiarizados com o pensamento de Laclau e Mouffe, que há outras discussões teórico-filosóficas igualmente relevantes na e para a TD, como as contribuições da psicanálise - aqui abordarei apenas alguns pontos - e a crítica pós-marxista ${ }^{1}$. Todavia, essas questões não serão abordadas no presente estudo, tendo em vista a exigência de um esforço mais específico do que se pretende realizar aqui.

Além desta introdução, o artigo conta com mais duas seções. Inicio a primeira seção discutindo as críticas pós-fundacionalista e pós-estruturalista, as quais destacam as contribuições do pensamento heideggeriano e derridiano na construção teórica da TD. Na sequência, abordo as noções de sedimentação e reativação, desenvolvidas a partir da fenomenologia de Husserl. Na terceira parte da primeira seção, discorro sobre as ideias de sobredeterminação e totalidade social, problematizadas pela TD a partir de reflexões althusserianas. Na segunda seção, apresento conceitos centrais para a compreensão do pensamento de Laclau e Mouffe, como estruturação discursiva e produção de sentidos, prática articulatória, exterior constitutivo e pontos nodais. Cumpre notar que as noções e conceitos a serem discutidos na segunda seção surgem interligados no interior do pensamento dos autores, sendo impossível um exercício de completa separação, mesmo para fins analítico-didáticos. Tendo isso em vista, na segunda parte do artigo a discussão privilegiará uma abordagem de conjunto de noções e conceitos, bem como procurará interligar as subseções, para não colocar em questão a unidade e a compreensão da TD.

\section{DIÁLOGOS E PERSPECTIVAS SOBRE O STATUS ONTOLÓGICO DA TD: CRÍTICA PÓS-FUNDACIONALISTA E PÓS-ESTRUTURALISTA}

A crítica pós-fundacionalista pode ser entendida, conforme Mendonça e Rodrigues (2014), como uma perspectiva filosófica que surge nos debates teórico-epistemológicos a partir de meados do século XX. Naquele contexto, como destacam os autores, buscava-se problematizar, com base em diferentes abordagens teóricas, concepções já sedimentadas no campo científico, como o positivismo lógico, a metafísica e o estruturalismo clássico ${ }^{2}$.

Elementar à crítica pós-fundacionalista, como destaca Marchart (2009), é sua distinção respeitante às concepções antifundacionalista e fundacionalista. Começarei pelo debate com o "antifundacionalismo". 
As concepções antifundacionalistas destacam a "negação final" da noção de fundamento, isto é, assumem a invalidação de toda possibilidade de estabelecimento de fundamentos à estrutura. Contrariamente a essa leitura, a crítica pós-fundacionalista não tem por objetivo uma completa negação da ideia de fundamento, mas busca "debilitar seu status ontológico" (Marchart, 2009:15³). Esse debilitamento ontológico do fundamento não significa uma defesa da total impossibilidade do estabelecimento de fundamentos, mas, o que é radicalmente diferente, a impossibilidade de um fundamento final, definitivo. Como destaca Marchart, isso implica "a crescente consciência, por um lado, da contingência e, por outro, do político como o momento de um fundar parcial e, em definitivo, sempre falido" (ibid:15).

A crítica pós-fundacionalista, portanto, não nega o princípio do fundamento, mas busca subverter as premissas das perspectivas fundacionalistas, sem cair na mera inversão da noção de fundamento final, como ocorre na crítica antifundacionalista, que recusa a possibilidade de estabelecimento de fundamentos. Surge, assim, o argumento do princípio de fundamento precário, contingente, instável.

Essa noção de contingência ${ }^{4}$, fortemente presente na Teoria do Discurso em Laclau e Mouffe, evidencia a recusa de concepções que aceitam fundamentos normativos estáveis, e, por conseguinte, conduz à aceitação do caráter precário, parcial e histórico dos fundamentos, em substituição à ideia de fundamento último. Ao evidenciar o caráter contingencial de toda fixação de sentidos, a crítica pós-fundacionalista, cuja base pode ser remetida a Heidegger e a Derrida ${ }^{5}$, compreende o social a partir das noções de ausência/falta e de fundamentos contingentes, ou fundamentos ausentes ${ }^{6}$.

O giro analítico do princípio de fundamento último para a ideia de fundamentos ausentes se deve à leitura heideggeriana de "abismo" ( $A b$ -grund) - e do pós-estruturalismo derridiano. Como destaca Marchart:

Este argumento se deve tanto a Martin Heidegger que não seria exagerado considerá-lo um dos principais "fundadores" do pós-fundacionalismo. Para Heidegger, a ausência do fundamento é própria da natureza de um abismo, ou seja, de um fundamento sem fundamento, de um fundamento sem fundo. Desse modo, a fundação, todavia acontece: a "função" do fundamento enquanto fundamento não desaparece por completo. Não 
obstante, acontece unicamente na medida em que passa através de um "a-bismo" que é o fundamento: o fundamento funda no abismo. (Marchart, 2009:34.; ênfases minhas)

A ideia de fundamento ausente, fundamento enquanto $A b$-grund, não significa ausência de fundamento ou, tampouco, que não exista fundamento algum, como na perspectiva antifundacionalista. Quando se faz referência ao "fundamento sem fundamento", como na citação acima, a preposição "sem" deve ser compreendida não como uma "ausência/ vazio radical", mas como uma ação de retirada, de apagamento da ideia forte de fundamento (seu debilitamento ontológico).

Contudo, faz-se necessário destacar que esse caráter debilitado do princípio de fundamento não é explicado pelo pós-fundacionalismo por uma impossibilidade empírica que, diante do excesso de fundamentos possíveis, torna impossível - do ponto de vista do fundacionalismo - a sua concretude: impossibilidade de estabelecimento de um fundamento diante da multiplicidade de possíveis fundamentos. É nesse ponto que pós-estruturalismo derridiano se mostra uma importante contribuição à discussão pós-fundacionalista.

Seguindo o pensamento derridiano, a impossibilidade de estabelecimento de um fundamento não deve ser compreendida a partir da ideia de excesso de sentidos possíveis, o que Derrida (2002) denomina de "estilo clássico" de análise, mas sim pela noção de falta, o que Marchart (2009) denomina de "hipótese pós-clássica". É a falta de um centro estável do jogo estrutural que impossibilita o estabelecimento de um fundamento final.

Esse giro evidencia que, na hipótese clássica ou no "estilo clássico" de análise, "evoca-se então o esforço empírico de um sujeito ou de um discurso finito correndo em vão atrás de uma riqueza infinita que jamais poderá dominar" (Derrida, 2002:244). Em outras palavras, compreende-se a impossibilidade da totalização devido à aceitação de uma infinitude empírica dos fundamentos, isto é, impera a leitura da existência de uma totalidade que não consegue abarcar a infinitude de sentidos presentes.

$\mathrm{Na}$ "hipótese pós-clássica", por sua vez, concebe-se a não totalização por outro ângulo analítico: 
[...] não mais sob o conceito de finitude como assignação à empiricidade mas sob o conceito de jogo. Se então a totalização não tem mais sentido, não é porque a infinidade de um campo não pode ser coberta por um olhar ou um discurso finitos, mas porque a natureza do campo - a saber a linguagem e uma linguagem finita - exclui a totalização: este campo é com efeito o de um jogo, isto é, de substituições infinitas no fechamento de um conjunto finito. Este campo só permite estas substituições infinitas porque é finito, isto é, porque em vez de ser um campo inesgotável, como na hipótese clássica, em vez de ser demasiado grande, lhe falta algo, a saber, um centro que detenha e fundamente o jogo das substituições. (Derrida, 2002:244-245; ênfases minhas)

A noção da ausência/falta destaca, ao mesmo tempo, a inexistência de um centro fundante, isto é, de um centro de origem do jogo estrutural, e a necessidade de existência de alguma ordem, de algum fundamento. Contudo, e isso deve ficar claro, não há, nessa leitura, a ideia de um centro imutável da estrutura. A não existência de um centro, por outro lado, não significa a ausência total de centro. O centro, na abordagem pós-estruturalista de Derrida (2002), deve ser entendido em termos de função: uma função organizativa da estrutura; uma função mais ou menos bem-sucedida, sendo e não sendo centro:

[...] o centro encerra também o jogo que abre e torna possível. Enquanto centro, é o ponto em que a substituição dos conteúdos, dos elementos, dos termos, já não é possível. No centro, é proibida a permuta ou a transformação dos elementos (que podem aliás ser estruturas compreendidas numa estrutura). Pelo menos sempre permaneceu interditada (e emprego propositalmente esta palavra). Sempre se pensou que o centro, por definição único, constituía, numa estrutura, exatamente aquilo que, comandando a estrutura, escapa à estruturalidade. Eis por que, para um pensamento clássico da estrutura, o centro pode ser dito, paradoxalmente, na estrutura e fora da estrutura. Está no centro da totalidade, e, contudo, dado que o centro não lhe pertence, a totalidade tem o seu centro noutro lugar. O centro não é o centro. $\mathrm{O}$ conceito de estrutura centrada - embora represente a própria coerência, a condição da episteme como filosofia ou como ciência - é contraditoriamente coerente. E como sempre, a coerência na contradição exprime a força de um desejo. O conceito de estrutura centrada é com efeito o conceito de um jogo fundado, constituído a partir de uma imobilidade fundadora e de uma certeza tranquilizadora, ela própria subtraída ao jogo. A partir desta certeza, a angústia pode ser 
dominada, a qual nasce sempre de uma certa maneira de estar implicado no jogo, de ser apanhado no jogo, de ser como ser logo de início no jogo. (Derrida, 2002:230-231; ênfases minhas)

Trata-se, portanto, de uma presença da falta, do vazio nos mesmos termos de Heidegger apresentado por Marchart (2009), que desconstrói ${ }^{7}$ a possibilidade de uma existência real, de um ponto de plena verdade, de um fundamento último à estrutura, sem desconsiderar a própria discussão sobre os fundamentos. Ou seja, essa desconstrução não significa um "giro para fora" da discussão sobre fundamentos, mas sim uma negação de fundamentos últimos. Mas essa falta é, ao mesmo tempo, constitutiva. Isso indica que, na impossibilidade de um centro fundante, de um fundamento último, abrem-se as possibilidades contingenciais de estabelecimentos de fundamentos parciais que cumpram a função de centro.

É a partir dessa leitura da impossibilidade de um fundamento último que Laclau (2000), discutindo a impossibilidade de estabelecimentos de fundamentos estáveis do social, argumenta sobre a ideia de "impossibilidade da sociedade". Essa impossibilidade se refere ao limite radical da compreensão da sociedade como um elemento autorreferente, como algo dado pela força do tempo, ou como possibilidade de uma sociedade uníssona, enquanto uma unidade fundamental de sentido. Nessa leitura, a sociedade, enquanto uma realidade-totalidade objetiva, só se constitui como resultado da sedimentação de fixações parciais e sobredeterminadas de sentidos (Laclau e Mouffe, 2015; Laclau, 2000; Marchart, 2009). Quando ela surge como uma "realidade objetiva", é devido ao efeito da sedimentação de sentidos enquanto tal. Disso decorre que o social não é pensado como um "jogo fechado", como possibilidade de instauração como uma realidade finalmente estabelecida, mas resultante de um projeto hegemônico sempre parcialmente bem-sucedido. As noções de sedimentação e reativação, discutidas na sequência, ajudam a obter uma melhor compreensão desse argumento.

\section{Sedimentação e reativação}

As noções de sedimentação e reativação são de grande importância para o constructo teórico de Laclau e Mouffe, e, dentre as categorias que estou a explorar no artigo, são as que menos foram debatidas 
pelos autores no sentido de evidenciar sua origem e modificações. Esse é o principal objetivo ao trazer essa discussão em sua origem, a fenomenologia de Husserl.

A partir de uma releitura de Husserl, sedimentação e reativação surgem na Teoria do Discurso na compreensão dos processos de hegemonização do social por um discurso (sua sedimentação) e nas lutas por novas hegemonias, momento em que se evidencia o caráter contingencial de toda estruturação social (momento da reativação, nos termos de Laclau e Mouffe).

Em Husserl, embora não explicitamente, podemos encontrar essas noções, sobretudo a de sedimentação, no escrito "A ingenuidade da ciência" (2009). Nesse artigo, Husserl critica tanto a pressuposição objetivista da razão, enquanto produtora de uma verdade em si que se reproduz rotineiramente no fazer ciência, quanto a desconsideração da historicidade das ciências que, mesmo quando acertadamente não nega o valor da história e da história da ciência, persiste em outra ingenuidade: a de não perceber a ciência como uma tradição acumulativa de tarefas de significação científico-objetiva do mundo da vida.

Essa dupla ingenuidade, como aponta Husserl (2009), leva a ciência moderna a um processo de tecnicização, distanciando-se da "fonte dos sentidos originais" pré-científicos do mundo da vida:

[...] um distanciamento de toda evidência original e das finalidades nelas reais e vitais, de modo que o sentido original e próprio da ciência pode se perceber dando lugar a um sentido sucedâneo. O método tecnicizado decorre de uma operação com signos e palavras irrefletidos, esvaziados de sua significação e de seus modos de validez originais e próprios. (Husserl, 2009:666 [Grifo meu])

A ideia de "distanciamento dos sentidos originais", um momento que pode ser entendido como "pré-discursivo", está diretamente relacionada ao afastamento/esquecimento do mundo da vida (Lebenswelt), que é, como argumenta Zilles (2002:32-33), “o âmbito de nossas originárias 'formações de sentido', do qual nascem as ciências (...) é um a priori dado com a subjetividade transcendental". A fenomenologia, tal qual a concebe Husserl, seria um exercício de evidenciação desses sentidos originais, movimento entendido pelo autor como reativa- 
ção. É a partir da ideia de reativação que Husserl "pretende retornar do mundo artificial e abstrato do objetivismo científico ao mundo da vida, buscando o saber fundamental no campo das experiências pré-científicas e originárias", em um exercício que visa "restituir o sentido originário às ciências a partir da 'função fundante' do 'mundo da vida', que é o problema anterior e universal para todas as ciências" (ibid: 40).

Esse "distanciamento de sentidos originais" é encontrado de forma mais clara em "A origem da geometria" (Husserl, 1989) e em sua clássica obra "As crises das ciências europeias e a fenomenologia transcendental" (2008) $)^{9}$. Em ambas as obras, Husserl percebe esse movimento de "distanciamento" como um processo passivo ${ }^{10}$ de "esquecimento" do "sentido original das coisas" promovido pela instituição da tradição científica (objetiva, positivista, matematizada etc.) desde Galileu. À fenomenologia transcendental, para Husserl, caberia a tarefa de reativação desses "sentidos originais", compreendidos como o momento "da autoexistência original, na imediaticidade [Aktualität] de sua primeira produção, ou seja, na 'evidência original' (...)" (Husserl, 1989: $163)^{11}$, cujo processo de sedimentação tende a esquecê-lo.

Em Husserl, a reativação, portanto, seria o processo de percepção "da autoexistência original", o momento da "significação-primeira" - da "evidência original" -, que se perde no processo de sedimentação, surgindo para a cultura presente como "tradições" já constituídas que "afirmam ser, por assim falar, sedimentações de um significado-verdade que pode ser tornado originalmente autoevidente" (Husserl, 1989:170). Ainda segundo Husserl:

É precisamente assim, fato inteiramente conhecido, assumido sem pensar, em vez de formulado como fato básico e escrutinado como tema próprio do pensamento; vale dizer que há duas verdades: por um lado, as verdades de situação prática cotidianas, sem dúvidas relativas, como já temos observado, exatamente o que a prática em cada caso busca e utiliza para seus propósitos. Por outro lado, as verdades científicas e sua fundamentação remetem precisamente a verdades de situação, mas de modo que o método científico, segundo seu próprio sentido, não padece, porque lá também ele necessariamente requer e deve fazer uso destas verdades. (2008:174) 
Não se trata, portanto, de verdades em si, mas de verdades aceitas pela força da sedimentação da tradição; um processo, segundo Husserl (2008), irrefletido da ciência enquanto uma tradição acumulativa e de uma consequente rotinização do fazer ciência:

Faltava então e falta, todavia, a verdadeira evidência, na qual quem conhece e produz pode justificar-se a si mesmo, não só a respeito do novo que produz, mas também a respeito de todas as implicações de sentido ocultas que mediante sedimentações, respectivamente, por obra da tradição, pode dar conta de pressuposições de suas configurações, conceitos, proposições, teorias. (2008:95)

Essa evidência só se torna clara quando se percebe a historicidade inerente a todo fato humano, ainda que implicitamente. Acontece que essa historicidade, que é "o movimento vital da coexistência e do entrelaçamento de formações originais e sedimentações de significados" (Husserl, 1989:174), possui uma estrutura interna de significados que não pode ser acessada por uma história meramente factual, pois esta, ao ficar restrita à ingenuidade da desconsideração da historicidade (Husserl, 2009), não se volta aos "sentidos originais", mas parte do plano das tradições já sedimentadas.

A noção de sedimentação, enquanto rotinização e esquecimento das origens dos sentidos, e a noção de reativação, enquanto retorno à situação originária de significação, são retomadas por Laclau $(2000,2014)$ em sua reflexão sobre os atos de instituição do social. Neste autor, a noção de sedimentação representa o êxito de um ato de instituição do social enquanto uma realidade objetiva. Como destaca:

Na medida em que um ato de instituição tem sido exitoso, tende a produzir um "esquecimento das origens"; o sistema de possibilidades alternativas tende a desvanecer-se, e os traços da contingência originária a apagar-se. Desse modo, o instituído tende a assumir a forma de uma mera presença objetiva. Este é o momento da sedimentação. É importante ver que este apagar-se implica um ocultamento. (Laclau, 2000:51)

Contudo, ao considerar a heterogeneidade radical do campo discursivo e o caráter contingencial de todo ato decisional (Laclau e Mouffe, 2015; Laclau, 2000, 2014), chega-se à conclusão de que a objetividade 
do social sempre envolverá a exclusão de alternativas; será sempre uma "totalidade contingente". Como pensar a sedimentação nestes termos? O que pode ocorrer neste processo

[...] é que a sedimentação pode ser tão completa, o privilégio de um dos polos da relação dicotômica tão garantido, que o caráter contingente deste privilégio, sua dimensão originária de poder, não resulta imediatamente visível" (Laclau, 2000:51).

O que Laclau está a argumentar é que a sedimentação ocorre por um ato radicalmente político de instituição de fundamentos. E isso tem reflexos diretos nas práticas políticas cotidianas. Em trabalhos recentes (Marques, 2015, 2016, 2019), problematizei dois conceitos antagônicos que se fazem presentes na formulação de políticas públicas culturais, o conceito de Democratização Cultural e o de Democracia Cultural. O primeiro parte da compreensão de que os déficits culturais de uma população podem ser problematizados e sanados por meio do consumo e da interação cultural pautados nos gostos legítimos do "grande patrimônio". Esta perspectiva compreende que o acesso dos sujeitos aos espaços culturais tradicionais, como museus, galerias de arte etc., bem como a interação com as expressões da cultura erudita, seriam suficientes e desejáveis para uma "educação cultural" capaz de promover a "elevação do nível cultural" dos sujeitos. Subjaz a essa abordagem um processo de hierarquização entre os níveis culturais, tomando o erudito como paradigma orientador das ações. Como destaquei nesses trabalhos, por cerca de meio século essa concepção orientou as políticas culturais (não só no Brasil). Encontrava-se sedimentada no discurso político corrente desde as primeiras experiências de políticas públicas culturais no Brasil. Só muito recentemente, a partir dos anos 2000, é que houve um processo de problematização desses pressupostos tomados como fundamentos das políticas culturais (reativação segundo a compreensão de Laclau). A partir de então, buscou-se uma nova fundamentação para essas políticas no sentido de uma ampliação do próprio conceito de cultura, que, ao buscar a ruptura com o modelo hierarquizado de cultura, passou a destacar e a valorizar expressões culturais que não se limitam apenas àquelas relacionadas ao erudito ${ }^{12}$. Ou seja, houve um processo de reativação dos fundamentos das políticas culturais e a busca por um novo modelo orientador que, ao longo dos anos 2000, buscou se sedimentar como nova orientação política: a Democracia Cultural (Marques, 2015, 2019; Lopes, 2007). 
Nessa retomada de Husserl por Laclau, a ideia de sedimentação não sofre muitas modificações, a não ser por sua perspectiva política mais explícita no pensador argentino - sedimentação enquanto "situação de hegemonia"13. $\mathrm{O}$ mesmo não pode ser dito em relação à noção de reativação.

Em Laclau (2000, 2014), o exercício de reativação não significa um movimento transcendental de retorno à situação originária, ao "da autoexistência original", mas de desconstrução do caráter objetivo de toda tentativa de sedimentação do social ${ }^{14}$. O que Laclau busca destacar é que esse momento da "significação-primeira" já evidencia, em si mesmo, o caráter contingente de todo ato de decisão. Ou seja, no pensamento laclauniano não há espaço para um retorno à "evidência original" à la Husserl que já não tenha sido discursivamente significado; esse momento, um momento de fundamentação, evidencia a exclusão de alternativas: algo foi fundamentado, instituído, em detrimento de outra coisa. Assim, para Laclau:

O momento da reativação não pode, contudo, em nosso caso, consistir em uma volta às origens, ao sistema histórico de possibilidades alternativas que foram descartadas. Recordemos o que assinalamos antes: as alternativas descartadas não implicam tudo que é logicamente possível mas tão somente aquelas possibilidades que foram efetivamente intentadas, que representaram, portanto, alternativas antagônicas e que foram suprimidas (...). A reativação não consiste, pois, em um retorno à situação originária, mas tão só em redescobrir, através da emergência de novos antagonismos, o caráter contingente da pretendida "objetividade". Mas este redescobrimento pode, por sua vez, reativar a compreensão histórica dos atos originários de instituição, na medida em que formas intumescidas, que eram consideradas como simples objetividade e dadas por sentadas, se revelam agora como contingentes e projetam essa contingência as suas próprias origens. (Laclau, 2000:51)

Pelo exposto, destaca-se que todo ato de sedimentação carrega consigo as marcas de sua radical contingência, pois, por mais abrangente que seja, um discurso não consegue abarcar a totalidade social; sempre haverá, portanto, um espaço para o indecidível, sempre estará marcado pela exclusão de alternativas em um contexto sobredeterminado. Nesse sentido, a instituição do social será sempre um processo político mais ou menos bem-sucedido de sedimentação. Essas questões têm profundas consequências na forma como Laclau e Mouffe constroem 
sua filosofia política (Democracia Radical e Plural) e auxiliam a pensar a intervenção política sobre questões sedimentadas na sociedade, indo desde a fundamentação de certos sentidos no processo de formulação de políticas públicas até as reflexões sobre a fundamentação de sentidos sobre noções como cidadania e família ${ }^{15}$.

\section{Sobredeterminação e totalidade social}

A relação entre sobredeterminação e totalidade social deriva da retomada das construções althusserianas. Como argumentam Laclau e Mouffe (2015), Althusser foi quem mais avançou no debate marxista ao argumentar, dialogando com a Linguística e com a Psicanálise, que toda formação social resulta de um fenômeno de sobredeterminação. Disso se compreende que não há uma causa única suficiente para explicar a sua ocorrência, o que, a princípio, levaria a um processo de recusa da determinação econômica em última instância na análise social marxista. No entanto, tal recusa não se deu no pensamento althusseriano.

Embora Althusser não tenha levado seu argumento às últimas consequências, rompendo definitivamente com o determinismo econômico, conforme sustentam Laclau e Mouffe (2015), sua argumentação permitiu uma abertura no interior do debate marxista contemporâneo. A noção de sobredeterminação, inaugurada por Althusser, advoga que a formação social não possui um único elemento organizador.

Ao assumir as perspectivas pós-fundacionalista e pós-estruturalista, Laclau e Mouffe argumentam que toda estrutura social é fundada a partir de uma lógica (discursiva) decisória, ou seja, se constitui a partir de práticas discursivas que buscam estabelecer fundamentos do social. É nesse sentido que Laclau e Mouffe (2015:37) concebem o social "como espaço discursivo - ou seja, que possibilita relações de representação estritamente inconcebíveis no interior de um paradigma fisicista ou naturalista".

Como resultado de relações de representação, o social sempre será o resultado de esforços de particularidades que, por meio de mecanismos hegemônicos (sedimentação), tendem a assumir a representação da totalidade. Concebido como um espaço discursivo e politicamente 
instituído, o social deixa de ser percebido como um "jogo fechado", como uma "totalidade fundante que se apresenta a si mesma como um objeto inteligível do 'conhecimento'" (Laclau, 2000:104):

[...] hoje em dia tendemos a aceitar a infinitude do social, quer dizer, o fato de que todo sistema estrutural é limitado, que está sempre rodeado por um "excesso de sentido" que ele é incapaz de dominar e que, em consequência, a "sociedade" como objeto unitário e inteligível que funda seus processos parciais, é uma impossibilidade [...]. O social não é tão somente o infinito jogo das diferenças. É também o intento de limitar este jogo, de domesticar a infinitude, de abarcá-la dentro da finitude de uma ordem. Mas esta ordem - ou estrutura - já não representa a forma de uma essência subjacente do social; é, ao contrário, o intento de atuar sobre o "social", de hegemonizá-lo. (Laclau, 2000:104-105)

Afirmar que toda ordem discursiva - ou estrutura, como Laclau chama atenção na citação acima - é sobredeterminada e efeito de uma particularidade que se apresenta como universal, não significa, em absoluto, que não seja possível falar em totalidade. Não se trata de uma negação radical da noção, mas de pensá-la a partir de pressupostos não essencialistas, percebendo-a sempre como efeito de representação do universal por particularidades (indeterminadas, vale frisar). Nesse exercício, o social deixa de ser concebido como uma ingênua redução teórica de uma ideia de totalidade última, como um "todo constituído" (fundamento final), e se apresenta como uma realidade precária, contingencial. Como destaca Laclau:

[...] o problema da totalidade social se coloca em novos termos: a "totalidade" não estabelece os limites "do social" mediante a transformação deste último num objeto determinado (quer dizer, a "sociedade"). Pelo contrário, o social sempre excede os limites de todo intento de constituir a sociedade. Ao mesmo tempo, contudo, a "totalidade" não desaparece: se a sutura que ela almeja é em última instância impossível, resulta possível, porém, proceder a uma fixação relativa do social através da instituição de pontos nodais (...). Cada formação social tem suas próprias formas de determinação e de autonomia relativa, que são sempre instituídas através de um complexo processo de sobredeterminação e não podem, por conseguinte, ser estabelecidas a priori. (Laclau, 2000:105) 
A totalidade, ou se preferirmos, toda ordem (ou ainda, estrutura), não determina os limites do social, como afirmado por Laclau na citação acima, porque este resulta de "efeitos totalizantes" do discurso que, ao lograr hegemonizar-se (sedimentar-se), busca ocultar o caráter sobredeterminado, portanto radicalmente indeterminado e contingente do social. Esse ocultamento do caráter contingencial do ato de instituir é levado a cabo como efeito ideológico do discurso. Em outras palavras, a função da ideologia no discurso - e aqui se limita o espaço que a categoria "ideologia" possui na teoria laclauniana - é garantir a sedimentação discursiva do social como uma verdade, implicando, nos termos de Laclau (2000), um “ocultamento das origens", isto é, uma espécie de "des-historicização" da construção do discurso que encoberta o fato de que todo ato decisional ocorre através de decisões contingentes. Somente nestes termos se pode falar em totalidade social no pensamento laclau-mouffeniano.

\section{NOÇÕES CENTRAIS DA TEORIA DO DISCURSO}

Essa retomada do status ontológico da Teoria do Discurso (TD) se faz necessária tanto para destacar algumas questões teórico-filosóficas que nem sempre são objeto de uma discussão mais detida por parte dos autores, como para uma melhor compreensão dos conceitos centrais da TD. Como argumentei na introdução deste artigo, certamente outras noções poderiam integrar o que estou a denominar de status ontológico da TD, como a contribuição da psicanálise freudo-lacaniana, o pós-marxismo, a linguística, dentre outras. Todavia, limitei-me às categorias ora apresentadas por considerar necessária uma problematização mais detalhada e por estarem diretamente relacionadas aos conceitos desenvolvidos por Laclau e Mouffe. O mesmo poderia ser dito sobre a opção de algumas noções e conceitos a serem discutidos nesta seção. De toda a forma, devido aos limites inerentes a um artigo, não seria possível abordar de maneira mais abrangente e aprofundada as discussões teórico-filosóficas e o constructo conceitual que embasam o pensamento dos autores. Deste modo, na sequência do artigo, explorarei os conceitos centrais da TD com o intuito de informar ao leitor os caminhos para uma melhor compreensão da referida teoria. 


\section{Estruturação discursiva e produção de sentidos}

A produção de sentidos ocorre a partir do momento contingencial portanto indeterminado - em que diferentes elementos, isto é, diferentes particularidades discursivas dispersas no campo da discursividade, iniciam uma relação articulatória, criando uma cadeia de equivalências. Nesse processo de articulação, os elementos passam a ter suas particularidades discursivas modificadas, tornando-se momentos em relação à articulação que passaram a estruturar. É desse processo que surgirá uma unidade de sentido, ou seja, um discurso:

[...] chamaremos articulação qualquer prática que estabeleça uma relação entre elementos de tal modo que sua identidade seja modificada como um resultado da prática articulatória [transformando-se em momentos]. A totalidade estruturada resultante desta prática articulatória, chamaremos de discurso. (Laclau; Mouffe, 2015:178 [acréscimo meu])

Cumpre notar que discurso, na perspectiva da TD, não se limita a uma simples ideia de elementos linguísticos, isto é, aos enunciados. $\mathrm{Na}$ presente teoria, as práticas são igualmente percebidas como discursos, uma vez que os "elementos linguísticos e não linguísticos não são meramente justapostos" (Laclau e Mouffe, 2015:182). Assim, destaca-se uma relação direta que não permite distinguir práticas discursivas e não discursivas. É nesse sentido que os autores sustentam que:

[...] a) todo objeto é constituído como objeto de discurso, uma vez que nenhum objeto é dado fora de condições discursivas de emergência; e b) qualquer distinção entre o que usualmente se chama de aspectos linguísticos e comportamentais de uma prática social ou é uma distinção incorreta, ou deve ter lugar como diferenciação na produção social de sentido, que é estruturada sob a forma de totalidades discursivas. (Laclau e Mouffe, 2015:180)

Sobre isso, duas observações são feitas pelos autores. A primeira diz respeito à afirmação de que todo objeto é constituído como objeto de discurso. Isso não significa que exista um mundo que escape ao pensamento, bem como não indica que há uma oposição entre realismo e idealismo. Os objetos existem no mundo, e isso é fato, mas suas especificidades, a forma como são significados, dependerá dos sentidos atribuídos discursivamente pelos sujeitos. Não se nega, portanto, 
que tais objetos "existam externamente ao pensamento, mas antes a afirmação bastante diferente de que eles próprios possam se constituir como objetos fora de qualquer condição discursiva de emergência" (Laclau e Mouffe, 2015:181).

Isso ajuda a compreender, por exemplo, o processo de significação dos lugares de memória da construção social da memória coletiva de um determinado grupo. Na impossibilidade de um centro fundante, de uma verdadeira origem do social, os sujeitos, jogados no mundo, se lançam na busca por fundamentos que cumpram essa função. Pensando em termos da construção da memória, isso significa que se abrem possibilidades de diferentes significações da ideia de memória, tornando-a possível como um esforço parcial de construção dos mitos de origem de um determinado local, de uma determinada cultura, sempre em disputa e em um processo contínuo de (re)invenção (Hobsbawm, 2008; Guarinello, 1994). Nesse processo discursivo, evidenciam-se as evocações dos lugares de memória, entendidos de forma ampla como lugares espaciais, lugares abstratos, lugares simbólicos, monumentos, festividades, datas, dentre outros que passam a ser mobilizados pelos sujeitos na construção da memória (Nora, 1993). Embora os lugares de memória, sobretudo os lugares físico-naturais, sejam espaços que "sempre estiveram ali", nem sempre "existiram" como pontos de identificação na construção discursiva da memória coletiva dos sujeitos. Os "lugares" só se tornam lugares de memória quando significados pelos sujeitos como pontos de identificação na estruturação discursiva. Esse processo, contudo, deve ser compreendido a partir do contexto, das inter-relações dos sujeitos entre si e com outros grupos sociais ou com a esfera institucional (política ou econômica) - na sequência, abordarei essa relação com o "outro" pela noção de "exterior constitutivo" -, pois nem todos os objetos do mundo da vida são significados como lugares de memória, ou não são significados como tais em um determinado momento.

A segunda observação decorre da primeira. Pode-se compreender, equivocadamente, que o discurso possui um caráter meramente mental. Laclau e Mouffe (2015:81) são enfáticos quanto a esse aspecto: "Contra isso, afirmaremos o caráter material de toda estrutura discursiva". O que deve ficar claro é que os autores não realizam uma distinção entre aspectos linguísticos e não linguísticos, entre verbalização e prática; tanto uma quanto outra já estão carregadas de sentidos. 
Estes elementos, certamente, já são suficientes para uma definição mais geral de discurso: uma prática (ações e enunciados) que resulta de processos articulatórios voltados para a produção de uma determinada unidade de significação da realidade que, como tal, busca se sedimentar enquanto uma verdade última na organização das relações sociais (Laclau e Mouffe, 2015; Laclau, 2000). Mas isso não é tudo.

Embora essa definição indique que os sentidos são produzidos por discursos e que estes buscam sedimentar-se enquanto ordenamento do social, o que significa que toda realidade social é um constructo de uma estruturação discursiva, ela não dá conta da complexidade que envolve o conceito: por exemplo, nada diz sobre como os discursos são articulados. Esse será o objetivo da próxima subseção.

\section{PRÁTICA ARTICULATÓRIA E O EXTERIOR CONSTITUTIVO}

Duas observações devem ser feitas a partir da definição anteriormente apresentada do conceito de discurso. Primeira, os processos articulatórios, ou práticas articulatórias, não ocorrem por meio de uma coerência lógica entre os elementos que os constituem, "nem por um sujeito transcendental apriorístico, um sujeito atribuidor de sentido à la Husserl, ou pela unidade de uma experiência" (Laclau e Mouffe, 2015:178).

Não há coerência lógica, porque os fatores que levam diferentes elementos (particularidades discursivas) a se articularem não são aquilo que podem ter em comum, mas, ao contrário, são fatores externos aos elementos e que mantêm uma relação de negatividade comum a todos. Noutras palavras, o que leva os elementos a se articularem é um "inimigo comum" que nega a constituição plena de todas as identidades da prática articulatória - é aqui que se encontra a equivalência entre os elementos: todos possuem uma relação de negatividade com um exterior comum (Laclau e Mouffe, 2015; Laclau, 2014).

Trazendo essa relação para as práticas políticas cotidianas, isso ajuda a entender, por exemplo, as articulações entre partidos, políticos e setores sociais em torno do significante "Diretas já" no contexto de luta pela redemocratização nacional nos anos $1980^{16}$. A campanha pelas "Diretas já", como destaca Mendonça (2006), foi um ponto nodal de diferentes discursos contrários ao regime militar. Havia um inimigo comum, o governo militar, na luta de diferentes setores da sociedade: 
[...] as "diretas já" constituiu-se num discurso privilegiado capaz de condensar múltiplas demandas dispersas entre si, num movimento que elegeu como corte antagônico um inimigo comum a todos os momentos articulados naquela vasta cadeia de equivalências: o regime político autoritário. Assim, se por um lado, a campanha das "diretas já" foi capaz de se constituir como um discurso hegemônico constituidor de uma ordem social entre todos seus elementos articulados, por outro lado, tornou-se também, em relação ao seu corte antagônico, um momento de profunda desestabilização de um regime político que, naquela época, perdurava já há vinte anos. (Mendonça, 2006:78)

Nos termos apresentados por Laclau e Mouffe, a coerência do processo articulatório deve ser entendida a partir da ideia de regularidade em dispersão. Essa ideia indica que, apesar dos elementos estarem dispersos no campo da discursividade, imersos no que os autores denominam de lógica da diferença, como no caso dos partidos, políticos e setores sociais antes das "Diretas já" - a princípio, havia pouca relação entre eles, ou relações indiretas, a não ser a luta contra um inimigo comum, isto é, o regime autoritário -, as diferentes formas de antagonismo, as diferentes lutas que cada uma dessas diferenças trava no social, podem fomentar uma relação de equivalências entre as diferenças no estabelecimento do conjunto de posições diferenciais (lógica da equivalência), iniciando, assim, uma articulação discursiva. $\mathrm{O}$ discurso que daí emerge já está marcado pela contingência, pois, com exceção do "inimigo comum", não há nada de necessário para a manutenção da articulação. No caso das "Diretas já", as décadas seguintes ao final da relação antagônica (o fim do regime militar) mostraram isso: a articulação logo se desfez e novos conflitos surgiram entre os elementos antes em articulação.

É nesse sentido que Laclau e Mouffe afirmam que a unidade discursiva não é uma unidade teleológica, não tem um sentido final, nem uma determinação apriorística; a articulação, como argumentam os autores, "é agora uma prática discursiva que não tem um plano de constituição anterior ou exterior à dispersão dos elementos articulados" (Laclau e Mouffe, 2015:183). Isso implica que a articulação ocorre sempre em relação a algo que excede os limites internos das particularidades (elementos). Essa relação com o exterior se baseia na noção derridiana de exterior constitutivo apontado por Staten $(1984)^{17}$. 
A partir de uma reflexão sobre a desconstrução em Wittgenstein e em Derrida, Staten (1984) argumenta que a constituição de uma posição diferencial, isto é, um processo de identificação ${ }^{18}$, depende de uma correspondência que, ao mesmo tempo em que a excede, a constitui, evidenciando a necessidade de uma relação com o externo para a constituição da "unidade interna" que , portanto, já não ocorre em termos de uma "unidade em si".

Isso significa que toda identificação se constitui por meio de uma diferença (différance), de uma relação com um "outro" que a constitui no entrecruzamento das fronteiras "interna" e "externa"; uma relação que, mesmo aceitando uma negação radical - isto é, antagonismo, como em Laclau (2014) - mantém um caráter necessário, porém não determinado, entre os lados fronteiriços (Staten, 1984; Mouffe, 2011, 2014).

Essa relação indica que os processos de identificação sócio-político-cultural não são identidades determinadas. O jogo se abre para as "identificações múltiplas", abertas, descentradas, que se constituem a partir das relações com o exterior. Nessa leitura, não há uma essência que escape a essas relações, e não há nada que as determine aprioristicamente. É nesse sentido que, como destaca Staten, Derrida, partindo de Aristóteles, problematiza o caráter acidental (contingencial) desse processo:

[...] cada tipo particular de coisa pode ter um acidente "especial" que será o limite apropriado para si próprio como tal, e irá constituí-lo como tipo particular como tal. Nesse sentido, de um "exterior constitutivo", o externo não é "acidental" como indeterminado, uma vez que é necessário para uma dada situação como tal; é acidental como não essencial que se abate sobre a essência. (Staten, 1984:16)

Conforme Staten (1984), esse movimento de Derrida o distancia da tradição transcendental de Kant-Husserl e evidencia que não há um sentido original da "coisa em si", do "objeto-em-geral", que não seja uma constituição positiva da conceptualidade filosófica. A marca forte de Derrida, e que também está presente no pensamento de Laclau e Mouffe, é o caráter contingencial dos processos de identificação, subvertendo a subordinação da "gramática da metafísica" do acidente à essência (Staten, 1984). Nesses termos, evidencia-se que o caráter acidental atravessa e constitui a identidade: "Já não basta notar e depois deixar de lado a contaminação factual ou empírica 
de nossas unidades, mas ver que elas são impuras sempre a princípio, e perseguir as implicações dessa lei essencial da impuridade" (Staten, 1984:19).

Uma "identidade", ou melhor, um processo de identificação, nessa perspectiva, estará sempre "contaminado" por um "algo além de si", isto é, o exterior constitutivo. Não há, portanto, uma forma própria, uma essência. Como destaca Staten:

A noção de exterior constitutivo é a desconstrução alternativa ao conceito filosófico fundamental de forma e essência - isto é, de unidade e autoidentidade como os mais gerais e invioláveis limites (seja estritamente transcategórico ou não) do ser do conhecimento. (Staten, 1984:23)

A questão problematizada por Staten não consiste de uma simples mudança de enfoque ou a mera substituição de uma lente de leitura por outra. Trata-se, ao estilo derridiano, de um estilo diferente de leitura: "A questão do estilo de desconstrução não é aquela sua relação com a verdade, mas sua relação com o discurso na verdade, isto é, a linguagem da filosofia" (Staten, 1984). A partir desse "estilo diferente", a ideia de "identidade integral", com seu "sujeito autossustentável", como destaca Hall (2000:103), passa a ser fortemente questionada e confrontada com a ideia de processos de identificação:

A identificação é, pois, um processo de articulação, uma suturação, uma sobredeterminação, e não uma substituição. Há sempre "demasiado" ou "muito pouco" - uma sobredeterminação ou uma falta, mas nunca um ajuste completo, uma totalidade. Como todas as práticas de significação, ela está sujeita ao "jogo" da différance. Ela obedece à lógica do mais-que-um. E uma vez que, como num processo, a identificação opera por meio da différance, ela envolve um trabalho discursivo, o fechamento e a marcação de fronteiras simbólicas, a produção de "efeitos de fronteiras". Para consolidar o processo, ela requer aquilo que é deixado de fora - o exterior que a constitui. (Hall, 2000:106)

A essa altura, deve estar claro que os processos de identificação ocorrem a partir das posições diferenciais; acontecem por meio da diferença, e isso é fundamental para a clarividência da noção de exterior constitutivo e sua importância nos processos de identificação. 
Trazendo a discussão para termos políticos, como destacam Laclau (2000), Mouffe $(2011,2012)$ e Hall $(2000,2011)$, significa que todo processo de identificação é relacional e essa relação é perpassada por atos de poder (atos de exclusão) na demarcação de um "nós" e de um "eles". Porém, vale destacar que, para Laclau (2000, 2014), esse processo será sempre marcado por uma exclusão radical, isto é, por relações antagônicas, no momento em que uma identidade é radicalmente negada enquanto uma totalidade objetiva.

Voltando ao que argumentei no início da seção, uma segunda observação deve ser feita sobre a prática articulatória: trata-se do processo de modificação das identidades diferenciais como resultado dessa prática, isto é, a passagem da situação de elementos para momentos. Como afirmei, ao estabelecerem uma prática articulatória, as identidades diferenciais, entendidas como elementos, tornam-se momentos em relação à articulação. Nesse processo, os elementos passam a partilhar conteúdos comuns com os outros elementos presentes na cadeia discursiva, ocasionando uma significativa modificação de suas identidades (Laclau e Mouffe, 2015; Laclau, 2011) - a forma como esse processo ocorre será discutida na próxima subseção, ao abordar os pontos nodais. Contudo, cumpre destacar que esse processo de modificação dos conteúdos particulares das identidades não é algo "sem volta", isto é, não há um completo esvaziamento dos conteúdos particulares dos elementos ao estabelecerem uma prática articulatória. Se isso ocorresse, não haveria nada de diferencial e nem de relacional numa prática articulatória; o resultado não seria uma articulação, que implica as lógicas de diferença e equivalência, mas um simples agrupamento entre iguais. Passado o "momento do conflito", os elementos retomam suas ações e novas articulações podem ocorrer. Discutirei, agora, como essa prática se estrutura.

\section{Pontos nodais e prática articulatória: estruturação do discurso}

Como abordei nas seções anteriores, na perspectiva da TD não é possível operar por meio de uma ideia absoluta de não fixação (antifundacionalismo), o que implicaria ausência completa de quaisquer fundamentos, nem em termos de uma fixação última de sentidos (fundacionalismo), o que remeteria à existência de um centro fundante. Nessa corrente teórica, a leitura se volta para a obtenção de fixações 
parciais de sentido (pós-fundacionalismo), as quais podem assumir, sempre de forma precária e contingencial, a função de centro (pós-estruturalismo).

Isso evidencia, como destaca Mendonça (2008:62), "que a prática articulatória não é um complexo dado e necessário, nem a simples soma de elementos, que articulados entre si, tornam-se momentos". A prática articulatória evidencia uma orientação, isto é, uma estrutura interna, ainda que contingente e precária. Essa orientação necessariamente partirá de uma identificação com os pontos nodais, sem os quais não é possível haver uma articulação.

A construção de Laclau e Mouffe (2015) da noção de pontos nodais se deve à ideia de point de capiton de Lacan. Como destaca Stavrakakis (2007), um point de capiton é um significante que exerce a função de deter o processo de significação do Real, conectando um significante a outro. Concebido como uma impossibilidade significativa, o que os sujeitos significam como Real é sempre o efeito de significações fantasmáticas sobre o Real, ou seja, são representações do Real, e nunca o Real-em-si. Porém, essas significações, vale destacar, não devem ser compreendidas como algo "irreal", mas como possibilidades de representação do Real que, como toda representação, será sempre falha, incompleta, parcial. Como o Real é uma impossibilidade enquanto plenitude, inalcançável, portanto, os sujeitos só podem existir no plano da fantasia, no registro do simbólico, na busca constante, e impossível, por uma completude.

É essa ideia de falta, presente também na discussão de Derrida (2002) acerca da ausência de um centro determinante da estrutura, que marca a constituição do social no pensamento de Laclau e Mouffe. Assim, sendo o social uma impossibilidade significativa plena, só é possível falar em significações parciais de sentido: o social é uma fantasia e sua representação será sempre limitada, parcial. Será a emergência dos pontos comuns de referência que conferirá certa ordem à cadeia de significantes na produção de um sentido. Na ausência desse ponto de referência, o point de capiton, o processo de significação tende a ser interminável:

O point de capiton é necessário no sentido de que, sem ele, não há nenhuma ordem; sua função implica a introdução de um princípio de ordenamento que torna possível a emergência do significado social e a construção da 
realidade. Sem a intervenção do point capiton, o mundo colapsa num universo psicótico. (Stavrakakis, 2007:97)

Nestes termos, o point de capiton é um "significante-referência" cujo significado pode ser produzido de diversas formas em relação à cadeia de significantes, o que quer dizer que este significante não é externo à prática articulatória: emerge a partir dela. Nesse sentido, nada pode determinar aprioristicamente qual discurso emergirá de uma cadeia de significantes como um discurso privilegiado (point de capiton). Isso implica, também, que a identificação do point de capiton só é possível a partir de uma atribuição retroativa ao processo de significação, isto é, posterior à formação discursiva (Stavrakakis, 2007).

Laclau e Mouffe (2015) recorrem a essas questões lacanianas para analisar os points de capiton como pontos nodais de um discurso. Concebidos a partir do vocabulário da TD, os pontos nodais podem ser analisados como pontos de interseção entre diferentes discursos na estruturação de uma formação discursiva:

Se o social não consegue fixar a si mesmo nas formas inteligíveis e instituídas de uma sociedade, o social só existe, no entanto, como um esforço para construir esse objeto impossível. Qualquer discurso se constitui como tentativa de dominar o campo da discursividade, de deter o fluxo das diferenças, de construir um centro. Chamaremos os pontos discursivos privilegiados desta fixação parcial de pontos nodais. (Laclau e Mouffe, 2015:187)

Da mesma forma que a ausência de points de capiton, na perspectiva lacaniana, impossibilita que o processo de significação se detenha, a ausência de pontos nodais, em termos da TD, impossibilita que uma formação discursiva seja levada a cabo: sem um ponto nodal, ou pontos nodais, os discursos em vias de articulação permanecem no âmbito da lógica da diferença, dispersos num amontoado de sentidos com diferentes direções - não há "ordem".

O ponto nodal, portanto, é um significante que, ao emergir da própria prática articulatória, consegue abarcar uma gama de diferentes significados a ponto de deixar de possuir um significado transparente para todos os elementos, pois deixa de ter um conteúdo particular; torna-se, nos termos de Laclau e Mouffe (2015), um significante vazio ${ }^{19}$, um processo que, como já destacado por Mendonça $(2008,2007)$, não ocorre aleatoriamente: 
[...] para que um discurso se torne um ponto nodal, é preciso, como já mencionamos, que este amplie seus conteúdos, incorpore elementos de outros discursos e necessariamente tenha de ceder alguns de seus sentidos iniciais para que estes não entrem em choque com sentidos produzidos por outras identidades por ele articuladas. (Mendonça, 2007:252)20

Quando esse momento é exitoso, os elementos passam a ter um ponto comum de referência, ou seja, um ponto nodal. Em relação a esse ponto, que cumpre a função de garantir certa unidade ao discurso e, portanto, de significar a própria prática articulatória, os elementos se transformam em momentos do discurso. Quer dizer, passam a incorporar à sua identidade outros conteúdos, ao mesmo tempo que seus conteúdos são universalizados na cadeia discursiva. Disso resulta a modificação das identidades na prática articulatória.

Contudo, como já destacado, a transformação de elementos em momentos não é total; os conteúdos particulares dos elementos nunca são totalmente eliminados - busquei destacar esse processo a partir da desarticulação dos elementos em torno das "Diretas já" após o término do governo militar; com a democratização e, com isso, com o fim do antagonismo com o regime ditatorial, os elementos voltaram a se dispersar a dar origem a outras articulações. Como também já abordado no exemplo das "Diretas já", toda articulação ocorre em relação a um exterior. Superada essa relação, e tendo em vista que os conteúdos particulares dos elementos não foram totalmente esvaziados, nada pode determinar a manutenção de uma prática articulatória, bem como as futuras articulações. É nesse sentido que Laclau e Mouffe destacam que:

A prática da articulação, portanto, consiste na construção de pontos nodais que fixam sentido parcialmente; e o caráter parcial desta fixação advém da abertura do social, resultante, por sua vez, do constante transbordamento de todo discurso pela infinitude do campo da discursividade. (Laclau e Mouffe, 2015:188)

Assim, nesse terreno aberto e indecidível, toda significação, por mais exitosa que possa ser, por mais profunda que possa ser sua sedimentação, resultará em atos de exclusão. Isso implica afirmar que nunca logrará articular em torno de si todos os discursos dispersos no campo da discursividade, evidenciando o caráter radicalmente contingencial de toda fixação de sentidos. 


\section{CONSIDERAÇÕES}

Ao longo deste artigo, abordei algumas das principais discussões e diálogos teóricos do pensamento laclau-mouffeniano, revisitando a crítica pós-fundacionalista e pós-estruturalista, os conceitos de sedimentação e reativação e as noções de sobredeterminação e totalidade social. Essa discussão se fez necessária para uma melhor compreensão da construção teórica dos autores, uma vez que suas bases nem sempre são expostas por meio de uma discussão mais detida por parte dos autores. Essa retomada, além de permitir uma melhor compreensão dos conceitos da TD, também auxilia na identificação de categorias centrais, como contingência, historicidade e hegemonia, presentes em diferentes abordagens que visam superar fundamentos epistemológicos estruturalistas e essencialistas.

A relevância desta discussão se deve, em muito, pelo destaque que o pensamento de Laclau e Mouffe tem no Brasil no contexto atual. Nos últimos anos, tem sido crescente o número de publicações de dissertações, teses, artigos e livros sobre ou produzidos a partir da TD, nos mais variados campos, como Administração, Antropologia, Educação, Sociologia, Ciência Política, Psicologia, Direito, dentre outros, distribuídos em diferentes centros de estudos e pesquisa nas universidades brasileiras. Ademais, com a recente publicação em língua portuguesa da principal obra dos autores, "Hegemonia e Estratégia Socialista: por uma política democrática radical", certamente o alcance da TD se ampliará, sobretudo nos cursos de graduação. Com isso, espero ter contribuído para uma "localização" da teoria em debate.

(Artigo recebido para publicação em 27 de setembro de 2018)

(Artigo reapresentado em 25 de setembro de 2019)

(Artigo aprovado para publicação em 12 de outubro de 2019)

\section{NOTAS}

1. Para uma discussão sobre o pós-marxismo na TD, conferir Laclau (2000:107-110; 111-145) e Burity (1997).

2. É de fundamental importância chamar a atenção para o fato de que existem diferentes abordagens teóricas pós-fundacionalistas e pós-estruturalistas (Peters, 2000; Williams, 2012; Mendonça e Rodrigues, 2014), o que significa que não se trata de uma "escola" e sim de um movimento filosófico contando com diferentes autores e perspectivas.

3. Todas as citações de obras em inglês e espanhol foram livremente traduzidas neste artigo. 
4. Segundo Abbagnano (2007:200), contingente, uma construção filosófica de influência árabe, é tudo que é, mas que poderia não vir a ser; é aquilo que é "não determinado", nem por isso impossível: "Desse ponto de vista, enquanto o possível não só não é necessário em si, mas tampouco é necessariamente determinado a ser, o C. é o possível que pode ser necessariamente determinado e, portanto, pode ser necessário".

5. Essa discussão também está presente em Mendonça, Linhares e Barros (2016).

6. Em nossa leitura da crítica pós-fundacionalista em Marchart, temos os fundamentos contingentes como sinônimo de fundamentos ausentes: "A 'contingência' como conceito não é senão o nome dado ao fundamento ausente desde o ponto de vista do discurso teórico e sobre a base do vocabulário tradicional e da reserva conceitual acessível dentro da teoria e da metafísica" (Marchart, 2009:50).

7. A expressão é aqui usada no sentido da desconstrução derridiana em sua crítica à metafísica ocidental. A discussão sobre a desconstrução, um "quase-conceito" apresentado pela primeira vez em Gramatologia, perpassa vários textos de Derrida em seu embate com o pensamento filosófico hegemônico em seu tempo. De uma forma mais ampla, a noção de desconstrução surge como uma "hipótese" contrária às teses de fechamento dos sentidos como "fonte de explicação" sedimentada pela metafísica da presença - digo hipótese devido ao cuidado que Derrida evidencia em não buscar "conceitos fechados", por isso "quase-conceito". Isso não significa passar de "um lado para o outro" a partir de uma simples substituição de preceitos, ou "destruição", do pensamento filosófico. A discussão de Derrida parte dos próprios discursos do pensamento ocidental para modificar e deslocar sua ordem conceitual; uma mudança de enfoque e não uma mudança absoluta. Além de Gramatologia (1973), as obras Margens da filosofia (1991) e A escritura e a diferença (2002) fornecem uma ampla discussão sobre a noção de desconstrução.

8. Por mundo da vida, como destaca Zilles (2002:32), “Husserl não entende, pois, o mundo de nossa atitude natural, na qual todos os nossos interesses teóricos e práticos são dirigidos aos entes do mundo. Na atitude fenomenológica trata-se de suspender nossa atenção nesse horizonte para ocupar-nos exclusivamente com o próprio mundo da vida, ou seja, como tem lugar para nós a permanente consciência da existência universal, do horizonte universal de objetos reais, efetivamente existentes".

9. Vale destacar que a obra As crises das ciências europeias e a fenomenologia transcendental apresenta diferentes edições. A edição de referência neste trabalho é da editora Prometeo (edição em espanhol). Esta edição não contém todos os textos dos anexos como presentes na versão em alemão da Biemel, publicada em 1976. Na edição em alemão, o texto "A origem da geometria" surge com o título "Beilage III" (365-386).

10. A passividade é entendida por Husserl (1989:165) como uma forma de pensar de modo repetitivo, "sem qualquer autoevidência com a atividade original". Ainda segundo o autor, "a passividade, em geral, é o reino das coisas que estão unidas e se fundem associativamente, onde todos os sentidos que surgem são colocados juntos passivamente".

11. Na tradução de John P. Leavey Jr. para o inglês, a passagem surge da seguinte forma: "The original being-itself-there, in the immediacy [Aktualität] of its first production, in original 'self-evidence'". A tradução para o português da expressão being-itself-there só foi completada como "autoexistência original" ao considerar a discussão mais geral de Husserl sobre os "sentidos originais" e ao recorrer à versão em alemão, na qual a expressão surge como Das originale Selbstdasein, derivando de Selbst-da. 
12. Para uma leitura sobre as mudanças nos paradigmas orientadores das políticas públicas culturais no Brasil, conferir também Albuquerque Júnior (2007), Barbalho (2007), Botelho (2007) e Calabre (2009).

13. Este argumento também se encontra na leitura de Mutzenberg (2003:45), ao destacar que a reativação em Laclau proporciona uma releitura radicalmente política da compreensão histórica da sedimentação, o que não significa um possível retorno às origens e sim uma "projeção da contingência originária do instituído".

14. Essa recusa a uma origem do sentido se deve à leitura derridiana de Laclau referente à inexistência de um centro fundante da estrutura, conforme abordado na primeira seção do artigo.

15. As possibilidades de reflexão a partir do pensamento de Laclau e Mouffe são muitas. Em outro trabalho (Marques, 2017), por exemplo, mobilizei o pensamento de Laclau e Mouffe para refletir sobre a noção de cidadania para além de um conceito puramente legal. Destaquei que, para um projeto de aprofundamento da experiência democrática, como almejado pelos autores, é necessário reativar os sentidos presentes na construção moderna do conceito de cidadania, problemarizando os princípios ético-políticos de liberdade e igualdade inerentes ao conceito moderno de política, para desconstruir o significante cidadania como um mero estatuto jurídico-legal relacionado aos direitos dos sujeitos garantidos pelo Estado. Também seria possível uma discussão sobre os sentidos sedimentados sobre o significante "família". A "família" não é um constructo natural, mas sim social; a configuração famíliar é plural. A sedimentação busca ocultar esse caráter e apresentar ao social uma única opção como "verdade": a família como fruto da união estável entre um homem e uma mulher. A luta pela reativação dos sentidos evidencia que esse "conceito" impede a plena realização de sujetos sistematicamente oprimidos. Essa tem sido parte das lutas de grupos da comunidade LGBTQI+.

16. Os exemplos poderiam ser variados; destacarei apenas mais um. Recentemente o país presenciou uma articulação em torno do significante \#EleNão. Em torno deste, diferentes grupos (elementos - particularidades discusivas), tais como as feministas, os coletivos e ativistas ligados a organizações de movimentos LGBTQI+ e ao movimento negro, coletivos culturais, setores sindicais, dentre outros, se articularam a partir de uma relação contra o discurso do então candidato à Presidência Jair Messias Bolsonaro. As manifestações do \#EleNão não resultaram do compartilhamento de "causas comuns" entre os elementos, mas da negação de um elemento comum a todos, o discurso do então candidato. O resultado desta articulação foi um discurso político mais abrangente do que os discursos de cada elemento em articulação tomados isoladamente - este fenômeno tem sido objeto de minhas reflexões em construção.

17. Como destaca Mouffe (2011:22), o termo exterior constitutivo "foi proposto por Henry Staten para se referir a uma série de temas desenvolvidos por Jacques Derrida em torno a noções como 'suplemento', 'traços' e 'différance'. O objetivo é destacar o fato de que a criação de uma identidade implica o estabelecimento de uma diferença, diferença construída muitas vezes sobre a base de uma hierarquia, por exemplo, entre forma e matéria, branco e negro, homem e mulher etc.".

18. O termo processo de identificação, como substituto à escrita "identidade", ganha em precisão teórica. A utilização do termo "identidade", pode ser percebida como apresenta Stuart Hall (2000:111-112): “Utilizo o termo 'identidade' para significar o ponto de 
encontro, o ponto de sutura, entre, por um lado, os discursos e as práticas que tentam nos 'interpelar', nos falar ou nos convocar para que assumamos nossos lugares como os sujeitos sociais de discursos particulares e, por outro, os processos que produzem subjetividades, que nos constroem como sujeitos aos quais se pode 'falar'. As identidades são, pois, pontos de apego temporário às posições-de-sujeito que as práticas discursivas constroem para nós. Elas são o resultado de uma bem-sucedida articulação [embora contingente] ou 'fixação' do sujeito ao fluxo do discurso (...). Isto é, as identidades são posições que o sujeito é obrigado a assumir, embora 'sabendo' (aqui, a linguagem da filosofia da consciência acaba por nos trair), sempre, que elas são representações, que a representação é sempre construída ao longo de uma 'falta', ao longo de uma divisão, a partir do lugar do Outro e que, assim, elas não podem, nunca, ser ajustadas - idênticas - aos processos de sujeito que são nelas investidos". Os termos colocados por Hall indicam justamente processos de identificação.

19. Como Laclau (2011:67) afirma categoricamente: “Um significante vazio é, no sentido estrito do termo, um significante sem significado". Um significante sem significado não quer dizer que não possua qualquer significado, e sim que não há significado particular. Um significante só se torna um significante vazio - pontos nodais e significantes vazios podem ser tomados como sinônimos - quando seu conteúdo particular "é 'esvaziado' de sua significação particular com o objetivo de representar a completude em geral e de poder articular um grande número de significantes heterogêneos" (Stavrakakis, 2007: 123).

20. Novamente destaco a recente mobilização em torno do \#EleNão (cf. nota 17). Inicialmente organizado por grupos feministas, o \#EleNão expandiu seus sentidos, passando a incorporar demandas diversas. $\mathrm{O}$ \#EleNão representou uma diversidade de sentidos direcionados a um "inimigo comum", deixando de ter um sentido em particular ou um sentido originalmente apresentado (se pensarmos que as mobilizações foram iniciadas pelas feministas). 


\section{REFERÊNCIAS}

ABBAGNANO, Nicola. (2007), Dicionário de filosofia. $5^{\text {a }}$ ed. São Paulo: Martins Fontes.

ALBUQUERQUE JÚNIOR, Durval M. (2007), “Gestão ou gestação pública da cultura? Algumas reflexões sobre o papel do Estado na produção cultural contemporânea". In: A. A. C Rubim; A. Barbalho (eds.), Políticas culturais no Brasil. Salvador: EdUFBA, pp. 61-86.

BARBALHO, Alexandre. (2007), "Políticas culturais no Brasil: identidade e diversidade sem diferença". In: A. A. C Rubim; A. Barbalho (eds.), Políticas culturais no Brasil. Salvador: EDUFBA, pp. 37-60.

BOTELHO, Isaura. (2007), "A política cultural e o plano das ideias", in A. A. C Rubim; A. Barbalho (Eds.), Políticas culturais no Brasil. Salvador: EdUFBA, pp. 109-132.

BURITY, Joanildo A. (1997), “Desconstrução, hegemonia e democracia: o pós-marxismo de Ernesto Laclau". Biblioteca Virtual de CLACSO. [Consult. 17-09-2019], s/p. Disponível em http:/ / biblioteca.clacso.edu.ar/Brasil/dipes-fundaj/20121129013954/joan7.pdf.

CALABRE, Lia. (2009), Políticas culturais no Brasil: dos anos 1930 ao século XXI. Rio de Janeiro: Editora FGC.

DERRIDA, Jacques. (1973), Gramatologia. São Paulo: Editora da Universidade de São Paulo. . (1991), Margens da filosofia. Campinas: Papirus. . (2002), A escritura e a diferença. $3^{\text {a }}$ ed. São Paulo: Perspectiva.

GUARINELLO, Noberto L. (1994), "Memória coletiva e história científica". Revista Brasileira de História, v. 14, n. 28 [Consult. 18-09-2019], pp. 180-193. Disponível em https:/ /www. anpuh.org/arquivo/download?ID_ARQUIVO=3763.

HALL, Stuart. (2000), “Quem precisa da identidade?”. In: T. T. Silva (org.) Identidade e diferença: a perspectiva dos estudos culturais. Petrópolis: Vozes, pp. 103-133.

. (2011), A identidade cultural na pós-modernidade. $11^{\mathrm{a}}$ ed., $1^{\mathrm{a}}$ reimp. Rio de Janeiro: DP\&A.

HOBSBAWM, Eric. (2008), "Introdução: A invenção das tradições”. In: E. Hobsbawm; T. Ranger (eds.), A invenção das tradições. 6. ${ }^{a}$ ed. Rio de Janeiro: Paz e Terra, pp. 9-23.

HUSSERL, Edmund. (2009), "A ingenuidade da ciência". Revista Scientiæ Studia, v. 7, n. 4 [Consult. 23-01-2016], pp. 659-670. Disponível em http:/ / www.scielo.br/pdf/ss/v7n4/ a08v7n4.pdf.

. (1989), "The origin of Geometry, by Edmund Husserl". In: J. Derrida. Edmund Husserl 's origin of geometry: an introduction. Trad. David Carr. Lincoln, University of Nebraska Press, pp. 155-180.

- (2008), La crisis de las ciencias europeas y la fenomenología trascendental. Buenos Aires: Prometeo Libros.

LACLAU, Ernesto. (2000), Nuevas reflexiones sobre la revolución de nuestro tempo. $2^{\mathrm{a}}$ ed. Buenos Aires: Nueva Visión. . (2011), Emancipação e diferença. Rio de Janeiro: EdUERJ. 
. (2014), Los fundamentos retóricos de la sociedade. Buenos Aires: Fondo de Cultura Económica.

; MOUFFE, Chantal. (2015), Hegemonia e estratégia socialista: por uma política democrática radical. São Paulo: Intermeios.

LOPES, João Teixeira. (2007), Da democratização à democracia cultural. Porto: Profedições.

MARCHART, Oliver. (2009), El pensamiento político posfundacional: La diferencia política en Nancy, Lefort, Badiou y Laclau. Buenos Aires: Fondo de Cultura Económica.

MARQUES, Marcelo de S. (2015), “Críticas ao Modelo hierarquizado de cultura: por um projeto de Democracia Cultural para as políticas culturais públicas". Revista de Estudios Sociales, n. 5, pp. 43-51 [Consult. 12-10-2019] 2019. Disponível em http:/ /www.scielo. org.co/pdf/res/n53/n53a04.pdf

(2016), “Cultura, poder e pluralismo cultural: uma análise inicial sobre o Palácio Anchieta". Revista Simbiótica, v. 03, n. 2, pp. 50-67, [Consult. 12-10-2019] 2019. Disponível em http:/ / periodicos.ufes.br/simbiotica/article/view/15075/10773

. (2017), "Cidadania: algumas considerações a partir da Democracia Radical e Plural". In: L. G. T. da Silva et al. (orgs.), Pós-estruturalismo e teoria do discurso: a obra de Ernesto Laclau a partir de abordagens empíricas e teóricas. Curitiba: CRV, pp. 209-223.

MARQUES, Marcelo de S. (2019), "Democracia Cultural, Estado e políticas públicas culturais: uma reflexão a partir da Democracia Radical e Plural". Colombia Internacional, v. 98, pp. 169-195, [Consult. 12-10-2019] 2019. Disponível em http: / / www.scielo.org.co/pdf / rci/n98/0121-5612-rci-98-00169.pdf

MENDONÇA, Daniel. (2006), Democracia sem democratas: uma análise da crise política no governo João Goulart (1961-1964). Tese (Doutorado em Ciência Política), Universidade Federal do Rio Grande do Sul, Porto Alegre.

"A teoria da hegemonia de Ernesto Laclau e a análise política brasileira". Ciências Sociais Unisinos. 2007, v. 43, n. 3 [Consult. 29-01-2016], pp. 249-258. Disponível em http:/ / www.redalyc.org/pdf/938/93843307.pdf.

. (2008), "A impossibilidade da emancipação: notas a partir da teoria do discurso". In: D. Mendonça; L. P. Rodrigues (eds.), Pós-Estruturalismo e Teoria do Discurso: em torno de Ernesto Laclau. Porto Alegre: EDIPUCRS, pp. 53-69.

MEDONÇA, Daniel; RODRIGUES, Léo Peixoto. (2014), “Do estruturalismo ao pós-estruturalismo: entre fundamentar e desfundamentar". In: D. Medonça; L. P. Rodrigues (eds.) Pós-estruturalismo e teoria do discurso: em torno de Ernesto Laclau. $2^{\text {a }}$ Ed. Porto Alegre, EDIPUCRS, pp. 27-45.

MENDONÇA, Daniel; LINHARES, Bianca de Freitas; BARROS, Sebastián. (2016), “O fundamento como 'fundamento ausente' nas ciências sociais: Heidegger, Derrida e Laclau". Revista Sociologia, v. 18, n. 41 [Consult 02-06-2016], pp. 164-194. Disponível em http:/ / www.scielo.br/pdf/soc/v18n41/1517-4522-soc-18-41-00164.pdf.

MOUFFE, Chantal. (2011), Em torno a lo político. $1^{\text {a }}$ ed. $2^{\mathrm{a}}$ reimp. Buenos Aires: Fondo de Cultura Económica. 
MOUFFE, Chantal. (2012), La paradoja democrática: el pligro del consenso en la política contemporánea. Barcelona: Gedisa.

. (2014), Agonística: pensar el mundo politicamente. Buenos Aires: Fondo de Cultura Económica.

MUTZENBERG, Remo. (2003), "Identidades e movimentos sociais numa sociedade indomável". Revista Política e Trabalho, n. 19 [Consult. 19-09-2019], pp. 39-58. Disponível em https://periodicos.ufpb.br/ojs/index.php/politicaetrabalho/article/view/6502/4067.

NORA, Pierre. (1993), “Entre memória e história: a problemática dos lugares". Proj. História, n. 10 [Consult. 17-09-2019], pp. 07-28. Disponível em https:/ / revistas.pucsp.br/revph/ article/view/12101/8763.

PETERS, Michael. (2000), Pós-estruturalismo e filosofia da diferença. Uma introdução. Belo Horizonte: Autêntica.

STATEN, Henry. (1984), Wittgenstein and Derrida. Lincoln: University of Nebraska Press.

STAVRAKAKIS, Yannis. (2007), Lacan y lo Político. Buenos Aires: Prometeo Libros.

WILLIAMS, James. (2012), Pós-estruturalismo. Petrópolis: Vozes.

ZILLES, Urbano. (2002), "A fenomenologia husserliana como método radical”. In: E. HUSSERL. A crise da humanidade europeia e a filosofia. Introd. e trad. Urbano Zilles. $2^{a}$ ed. Porto Alegre: EDIPUCRS, pp. 8-42. 


\section{RESUMO \\ Status Ontológico da Teoria do Discurso (TD) em Laclau e Mouffe: Diálogos, Perspectivas Teóricas e Conceitos Básicos}

Cada vez mais a Teoria do Discurso (TD) em Laclau e Mouffe tem sido problematizada e mobilizada, enquanto ferramenta teórica, epistemológica e metodológica, em diferentes campos do conhecimento, evidenciando seu caráter interdisciplinar. Contudo, algumas discussões teórico-filosóficas presentes nesta teoria ainda carecem de mais esclarecimentos, pois nem sempre são expostas por Laclau e Mouffe de forma mais desenvolvida. Diante disso, o objetivo deste artigo é retomar alguns elementos centrais que, ao ajudarem a delinear o status ontológico do pensamento laclau-mouffeniano, auxiliam na "localização" da teoria de forma mais ampla, permitindo ao público mais geral acessar algumas de suas principais bases de fundamentação. Com isso, espero contribuir para uma melhor compreensão da TD e de seus conceitos elementares.

Palavras-chave: Teoria do Discurso; Laclau e Mouffe; status ontológico

\section{ABSTRACT \\ Ontological Status of the Discourse Theory (TD) in Laclau and Mouffe: Dialogs, Perspectives and Basic Concepts}

The Discourse Theory (DT) of Laclau and Mouffe has been increasingly discussed and mobilized as a methodological, epistemological and theoretical tool in different areas of the knowledge, evincing its interdisciplinary character. Nevertheless, some philosophical and theoretical discussions presented in their theory lack clarity, since they are not always fully ellaborated by Laclau and Mouffe. Taking that into account, this article's aim is to revisit some central elements of Laclau and Mouffe's thought, by helping to delineate the ontological status of their work, and thus allowing us to "locate" the theory in a wider form, so that people with different backgrounds may access some of their fundamental aspects. Thus, I expect to contribute to a better comprehension of the DT in Laclau and Mouffe and of its basic concepts.

Keywords: Discourse Theory; Laclau and Mouffe; ontological status 


\section{RÉSUMÉ}

Le Statut ontologique de la théorie du discours (TD) à Laclau et Mouffe: Dialogues, Perspectives Théoriques et Concepts de Base

La Théorie du Discours (TD) à Laclau et Mouffe a été de plus en plus problématisée et mobilisée, tandis que l'outil théorique, épistémologique et méthodologique, dans différents domaines de la connaissance, montre son caractère interdisciplinaire. Cependant, quelques discussions théoriques et philosophiques présentent dans cette théorie manquent encore plus de précisions, parce que ne sont pas exposés completement par Laclau et Mouffe. Compte tenu de cela, l'objectif de cet article est de passer en revue certains éléments centraux qui, en aidant à décrire le statut ontologique de la pensée laclau-muffénienne, aident à la "localisation" de la théorie d'une manière plus large, permettant au grand public d'accéder à certaines bases de fondamentation. Sur ce, j'espère contribuer à une meilleure compréhension de la TD et de ses concepts élémentaires.

Mots-clés: Théorie du Discours; Laclau et Mouffe; statut ontologique

\section{RESUMEN}

Estatus ontológico de la Teoría del Discurso (TD) en Laclau y Mouffe: diálogos, perspectivas teóricas y conceptos básicos

Cada vez más la Teoría del Discurso (TD) en Laclau y Mouffe ha sido problematizada y movilizada, en tanto herramienta teórica, epistemológica y metodológica, en diferentes campos del conocimiento, evidenciando su carácter interdisciplinar. A pesar de eso, algunas discusiones teórico filosóficas presentes en esta teoría aún carecen de aclaraciones, pues no siempre son expuestas por Laclau y Mouffe de la forma más desarrollada. Frente a esto, el objetivo de este artículo es retomar algunos elementos centrales que, al ayudar a delinear el estatus ontológico del pensamiento laclau-mouffeniano, contribuyen en la "localización" de la teoría de forma más amplia, permitiendo al público más general acceder a algunas de sus principales bases de fundamentación. Con esto, espero contribuir para una mejor comprensión de la TD y de sus conceptos fundamentales.

Palabras clave: Teoria del Discurso; Laclau y Mouffe; estatus ontológico 